\title{
Skopi: a simulation package for diffractive imaging of noncrystalline biomolecules
}

\author{
Ariana Peck, ${ }^{\text {a,d }}$ Hsing-Yin Chang, ${ }^{\text {a,d }}$ Antoine Dujardin, ${ }^{a}$ Deeban Rama- \\ lingam, ${ }^{\text {a }}$ Monarin Uervirojnangkoorn, ${ }^{\text {a }}$ Zhaoyou Wang, ${ }^{\text {a }}$ Adrian Man- \\ cuso, $^{\mathrm{b}, \mathrm{c}}$ Frédéric Poitevin ${ }^{\mathrm{a}}$ and Chun Hong Yoon ${ }^{\mathrm{a} *}$ \\ ${ }^{\text {a }}$ Linac Coherent Light Source, SLAC National Accelerator Laboratory, 2575 Sand Hill Road, Menlo Park,

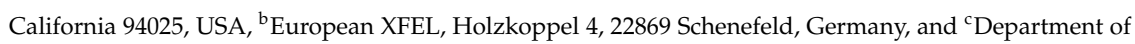 \\ Chemistry and Physics, La Trobe Institute for Molecular Science, La Trobe University, Melbourne, Victoria \\ 3086, Australia. ${ }^{d}$ These authors contributed equally to this work.. Correspondence e-mail: yoon82@slac.stanford.edu
}

X-ray free electron lasers (XFEL) have the ability to produce ultra-bright femtosecond X-ray pulses for coherent diffraction imaging of biomolecules. While the development of methods and algorithms for macromolecular crystallography is now mature, XFEL experiments involving aerosolized or solvated biomolecular samples offer new challenges both in terms of experimental design and data processing. Skopi is a simulation package that can generate single-hit diffraction images for reconstruction algorithms, multi-hit diffraction images of aggregated particles for training machine learning classification tasks using labeled data, diffraction images of randomly distributed particles for fluctuation X-ray scattering (FXS) algorithms, and diffraction images of reference and target particles for holographic reconstruction algorithms. We envision skopi as a resource to aid the development of on-the-fly feedback during non-crystalline experiments at XFEL facilities, which will provide critical insights into biomolecular structure and function.

\section{Introduction}

The unique capabilities of X-ray free electron laser (XFEL) sources have led to significant advances in structural biology since the first hard X-ray laser began operation at the Linac Coherent Light Source (LCLS) in 2009 (Spence, 2018; Jamison, 2010). The XFEL technique of serial femtosecond crystallography (SFX) has proven particularly transformative for protein crystallographers. Ultra-bright X-rays enable studying crystals too small or radiation-sensitive for synchrotron sources, while the femtosecond pulses have permitted time-resolved studies of enzyme catalysis at atomic resolution (Schlichting, 2015; Stauch \& Cherezov, 2018). By contrast, coherent X-ray diffractive imaging (CXDI) of non-crystalline biological samples has remained a largely nascent application, despite these experiments being the original intent of XFEL technology. Several studies have demonstrated successful single-particle imaging (SPI) of large targets such as viruses and organelles (Seibert et al., 2011; van der Schot et al., 2015; Brändén et al., 2019; Hantke et al., 2014), but 3D reconstruction has been limited to nanoscale resolution (Ekeberg et al., 2015; Rose et al., 2018; Kurta et al., 2017). Multi-particle techniques, including fluctuation X-ray scattering (FXS) (Mendez et al., 2014; Mendez et al., 2016; Kurta et al., 2017; Doniach, 2018; Pande et al., 2018) and holography (Gorkhover et al., 2018), have also been explored for structure determination. However, CXDI of noncrystalline biological samples remains far from routine, in contrast to the success of XFEL experiments of inorganic materials that provide significantly more signal (Ayyer et al., 2020). Improvements in resolution are needed before these techniques can address novel questions in structural biology.
The principal challenges faced by CXDI studies of noncrystalline samples are the low signal relative to instrumental background, sparsity of hits in the large volume of collected data, and intrinsic heterogeneity of the imaged particles (Bielecki et al., 2020; Daurer et al., 2017). Experimental advances have improved both sample delivery and the dynamic range of detectors, increasing the quality of the measured signal (Bielecki et al., 2019). Now some of the most pressing obstacles to achieving high-resolution reconstructions from these data are algorithmic in nature. In particular, rigorous classification is required both to identify the useful single-particle hits from shots of aggregates or no particles and to cluster images based on conformational heterogeneity (Maia et al., 2009; Yoon et al., 2011; Reddy et al., 2017; Cruz-Chú et al., 2021). In addition, more sophisticated background subtraction methods are needed to isolate the low-intensity particle scattering prior to reconstruction. While methods to perform classification and background removal have been explored and applied to the few experimental datasets available (Assalauova et al., 2020; Shi et al., 2019), it is unclear how well these algorithms will generalize to new experiments.

Realistic simulations of CXDI experiments could accelerate the maturation of this field by providing a test-bed for advanced data pre-processing and reconstruction algorithms. Condor is another open-source software available for CXDI simulations and was created to facilitate planning experiments at first-generation XFELs (Hantke et al., 2016). However, the ongoing development of different types of single particle imaging experiments with higher repetition rates and more sophisticated detectors poses new challenges and thus calls for tools 
capable of simulating these technological advances at scale. Here we present skopi, a software package designed for rapid and high-throughput simulations of SPI, FXS, and holography experiments on modern detectors. The simulated experiments are highly customizable and readily support modeling the beam characteristics and detectors available at LCLS. Skopi also makes it convenient to include diverse sources of noise, including fluctuating dark noise, beam miscentering, a static sloped background, and fluence jitter, all of which can impact reconstruction. Additional challenges inherent to biomolecular imaging, such as variable particle hydration and heterogeneity, can be simulated as well. We anticipate skopi will be a useful resource for developing new data processing algorithms, guiding experimental design, and in time aiding on-the-fly feedback during CXDI experiments of noncrystalline biological samples.

\section{Modular implementation}

The design of skopi is highly modular, with the three main components of a CXDI experiment - the particle, beam, and detector - agnostic to the type of experiment being simulated (Fig. 1). Each component can be modeled with a range of complexity, from the ideal case to more sophisticated representations that mimic experimental errors and noise. We briefly describe these components below.

The particle object stores the biomolecule's atomic coordinates and associated form factors. Conformational heterogeneity can be modeled by sampling along the particle's normal modes to generate alternate states; this is accomplished using the anisotropic network model from the ProDy package (Bakan et al., 2011) (Fig. S1A). Another source of sample heterogeneity is the disordered solvent shell surrounding aerosolized particles, which helps to preserve structural integrity in vacuum but increases shot-to-shot variation (Hau-Riege et al., 2007; Mandl et al., 2020). To account for this effect, skopi enables modeling a hydration layer that follows the particle's contour and has a variable width between shots (Fig. S1B).

The beam object contains information about the beam's dimensions, fluence, and wavelength spectrum. The simplest case models a single monochromatic spike with spatially uniform fluence. A more advanced option accounts for selfamplified spontaneous emission (SASE), which produces ultrabright pulses but broadens the beam's energy spectrum (Geloni et al., 2017). Skopi models SASE spectra as trains of uncorrelated spikes using a Gaussian kernel density estimate to approximate their energy distribution (Fig. S2). Noise can be added by modeling spatial variation of the fluence in the plane of the beam and by introducing jitter, in which shot-to-shot changes in total fluence are Gaussian-distributed.

The simplest detector is a monolithic square pixel array of user-defined dimensions. The diverse detectors in use at LCLS for CXDI experiments are also supported (Fig. S3A). Recently developed detectors, such as the Jungfrau and ePix10k, are implemented with an auto-ranging feature that avoids saturation to increase their dynamic range (Blaj et al., 2015; van Driel et al., 2020; Redford et al., 2018) (Fig. S3B). LCLS detectors also have access to the calibration constants and fluctuating dark noise from specific experiments (Fig. S4A). Once initialized with a beam, the detector object is populated with information about the pixels' position in reciprocal space, solid angle distended, and polarization. Finally, the detector object also supports modeling both beam miscentering, in which the beam's focus is displaced relative to the detector's center, and a userdefined sloped background to model parasitic scattering, which is a source of correlated noise that cannot be averaged away by merging more data (Fig. S4B-C).

Once the particle, beam, and detector are set up, any of the three principal CXDI experiments can be easily and efficiently simulated. Skopi provides convenient interfaces for each of the SPI, FXS, and holography experiment types, from which small or wide angle X-ray scattering (SAXS or WAXS) profiles can be derived through radial averaging. These interfaces act as wrappers for a common experiment class, recognizing that CXDI experiments are at their core very similar, differing only in the number, type, and relative position(s) of particle(s) in the beam (Fig. 2). For each shot, the particle or set of particles is randomly displaced and oriented in the volume intersected by the sample delivery jet and beam, and the coherent diffraction pattern is computed. To facilitate incremental testing of reconstruction algorithms, either the ideal intensities or quantized photons can be saved, in addition to the number of particles, particle orientations, and particle positions at each shot. Beyond Poisson error, more sophisticated types of noise can also be defined in configuring the experiment and individually tuned to achieve the desired signal-to-noise ratio.

\section{Benchmarking}

Skopi achieves rapid and high-throughput simulations of CXDI experiments through graphical processing unit (GPU) acceleration and parallelization. Because diffraction calculations scale linearly with particle size, the full 3D diffraction volume for each particle is computed when an experiment is first configured and thus represents a one-time cost (Fig. S5A). Diffraction images are then efficiently calculated by slicing through this pre-computed volume (Fig. S5B). The disadvantage of this approach is the inability to account for the stochastic effects of radiation damage during each interaction between the sample and beam; however, radiation damage is anticipated to be minimal for biological samples, particularly in comparison to instrumental background (Neutze et al., 2000; Östlin et al., 2019; Spence, 2017). On a single NVIDIA GeForce GPU, an SPI dataset acquired on a one megapixel PnCCD detector could be simulated at a rate of 0.6 diffraction patterns per second. This rate was reduced to 0.4 images per second for the SPI aggregate, FXS, and holography experiments due to the need to distribute clustered or dispersed particles in the beam for each shot. Dataset generation can be easily parallelized across an arbitrary number of GPU nodes to increase throughput.

\section{Validation}

We validated skopi by recovering the protein structure from simulated diffraction images of a chaperonin (PDB ID: 3iyf). SPI datasets consisting of $5 \mathrm{k}$ images each were generated in the 
absence or presence of noise on a PnCCD detector positioned for a resolution limit of $14 \AA$ at the edge of the detector. Reconstruction was performed using a Cartesian implementation of the multi-tiered iterative phasing (MTIP) algorithm (Donatelli et al., 2017; Dujardin et al., 2020). As expected, the protein structure was accurately recovered to a resolution of $15 \AA$ from noise-free diffraction images (Fig. 3). Poisson noise reduced the resolution of the recovered structure to $20 \AA$, and additionally introducing beam jitter degraded reconstruction quality further, as evident in the loss of the protein's eight-fold symmetry (Fig. 3). Skopi thus provides a useful tool to assess the tolerance of reconstruction algorithms to different types of noise.

\section{Conclusion}

Here we present skopi as a convenient tool to efficiently simulate CXDI experiments of noncrystalline biological samples. The modular design of this package makes it easy to represent each component of an XFEL experiment with a range of complexity, including modeling the most up-to-date features of current LCLS detectors (van Driel et al., 2020). Another focus of skopi is to produce simulated data with realistic noise. The different sources of error that typify CXDI experiments - including fluence jitter, beam miscentering, and fluctuating dark noise — can be readily incorporated into the simulation without additional scripting.

The paucity of experimental CXDI datasets of noncrystalline biological samples has hindered algorithmic growth in the field. We anticipate that skopi could help fill this gap by its ability to rapidly provide diverse simulated datasets with realistic noise. This may prove particularly valuable for the development of machine learning algorithms to perform classification, since labeled data can easily be generated in bulk. Classification algorithms would not only benefit data pre-processing to separate single-particle hits from aggregate shots, but could also be used during reconstruction to sort diffraction images based on the particle's conformation (Ignatenko et al., 2021), as done in cryo-electron microscopy (Punjani \& Fleet, 2021; Zhong et al., 2021; Chen \& Ludtke, 2021).

In addition to aiding algorithm development, we envision skopi as a critical tool for guiding experimental data collection at LCLS and other XFEL facilities through large-scale startto-end facility simulations (Yoon et al., 2016; Fortmann-Grote et al., 2017). By supporting both the advanced detectors currently in use at LCLS and the inclusion of fluctuating dark noise from past experiments, skopi enables simulating highly realistic diffraction patterns that would be obtained at this facility. These simulated datasets in turn provide an estimate of the available signal under different experimental conditions, potentially allowing settings to be optimized and offering an estimate of the volume of data required for reconstruction in advance of XFEL experiments.
Elements of theory. In this section, we summarize the main elements of coherent X-ray optics taken from (Paganin, 2006) that allow us to derive the diffraction model implemented in skopi. Propagation of electromagnetic waves $\Psi(\mathbf{r}, t)$ in nonmagnetic matter follows the wave equation, where the local velocity is modulated by the local electric permittivity $\epsilon$ while the magnetic permeability $\mu_{0}$ is assumed to be that of free space everywhere:

$$
\left(\epsilon(\mathbf{r}) \boldsymbol{\mu}_{0} \frac{\partial^{2}}{\partial t^{2}}-\nabla^{2}\right) \Psi(\mathbf{r}, t)=0
$$

Separation of temporal and spatial variables is assumed through spectral decomposition:

$$
\Psi(\mathbf{r}, t)=\frac{1}{\sqrt{2 \pi}} \int_{0}^{\infty} d \omega \phi_{\boldsymbol{\omega}}(\mathbf{r}) e^{-i \boldsymbol{\omega} t}
$$

where the frequency $\omega$ of each monochromatic wave is related to its wavevector modulus $k$ through the velocity of light in free space: $\omega=k c$. The effect of local perturbations can be factored in the refractive index $n_{\omega}(\mathbf{r})=c \sqrt{\boldsymbol{\epsilon}(\mathbf{r}) \boldsymbol{\mu}_{0}}$, which measures the relative velocity of light in the medium compared to free space. Inserting the spectral decomposition of the electromagnetic wave in the wave equation yields an inhomogeneous Helmholtz equation for each monochromatic wave:

$$
\left(\nabla^{2}+k^{2} n_{\omega}^{2}(\mathbf{r})\right) \phi_{\omega}(\mathbf{r})=0
$$

In free space, Eq. 3 simplifies to the homogeneous Helmholtz equation which can be solved and yields the following solution to the wave equation 1: $\Psi(\mathbf{r}, t)=\exp i(\mathbf{k} \cdot \mathbf{r}-\boldsymbol{\omega} t)$. The spatial wavelength $\lambda$ of this wave is such that $\cos k \lambda=1$, so the wavevector modulus is related to it through the relation $k=\frac{2 \pi}{\lambda}$.

More generally, it can be shown that Eq. 2 is equivalent to its integral-equation formulation, which involves the incident wave $\phi^{(0)}$ and a convolution with the Green's function $G_{\omega}=\frac{e^{i k r}}{r}$ :

$$
\phi_{\omega}(\mathbf{r})=\phi_{\omega}^{(0)}(\mathbf{r})-\frac{k^{2}}{4 \pi} G_{\omega} \star\left[\left(1-n_{\omega}^{2}\right) \phi_{\omega}\right](\mathbf{r})
$$

In the Born approximation, the wave function on the righthand side of Eq. 4 is assumed to be identical to the incident wave function, thus trivializing the integral equation formulation. Further assuming the case of Fraunhofer (far-field) diffraction and of an incident plane wave $\phi_{\omega}^{(0)}(\mathbf{r})=e^{i \mathbf{k}_{0} . \mathbf{r}}$, we can introduce the scattering amplitude $f(\Delta \mathbf{k})$ where $\Delta \mathbf{k}=k \frac{\mathbf{r}}{r}-\mathbf{k}_{0}$ :

$$
\begin{aligned}
& \phi_{\omega}(\mathbf{r})=e^{i \mathbf{k}_{0} \cdot \mathbf{r}}+\frac{e^{i k r}}{r} f(\Delta \mathbf{k}) \\
& f(\Delta \mathbf{k})=-\frac{k^{2}}{4 \pi} \int d \mathbf{r}^{\prime}\left(1-n_{\omega}^{2}\left(\mathbf{r}^{\prime}\right)\right) e^{-i \Delta \mathbf{k} \cdot \mathbf{r}^{\prime}}
\end{aligned}
$$

Assuming a specific relationship between the refractive index and the electron density of the object $\rho$, the scattering amplitude is scaled by the Thomson scattering length $r_{0}$ :

$$
f(\Delta \mathbf{k})=-r_{0} \int d \mathbf{r}^{\prime} \boldsymbol{\rho}\left(\mathbf{r}^{\prime}\right) e^{-i \Delta \mathbf{k} \cdot \mathbf{r}^{\prime}}
$$


Finally, noting $2 \theta$ as the angle between the incident and resulting wave vectors, we introduce the notation $\mathbf{s}=\Delta \mathbf{k}$ where $s=\frac{4 \pi}{\lambda} \sin \theta$. In the superposition approximation, the molecular electron density is approximated as a sum of individual atomic contributions. In diffraction space, the atomic form factors $f_{i}$ are tabulated as a function of $\sin \theta / \lambda$ :

$$
f(\mathbf{s})=-r_{0} \sum_{i} f_{i}\left(\frac{s}{4 \pi}\right) e^{-i \mathbf{s} . \mathbf{r}_{i}}
$$

The resulting structure factors $f$ can then be corrected for beam polarization and solid angle effects and corrupted with several types of noise that we encompass into functions $\alpha$ and $\beta$ to yield the intensity $I$. The diffraction intensity is quantized by drawing from the corresponding Poisson distribution $\mathcal{P}$ to simulate the photon counts $C$ measured on the detector:

$$
\begin{aligned}
I(\mathbf{s}) & =\alpha(\mathbf{s})|f(\mathbf{s})|^{2}+\boldsymbol{\beta}(\mathbf{s}) \\
C(\mathbf{s}) & =\mathcal{P}[I(\mathbf{s})]
\end{aligned}
$$

Implementation. In practice, Eq. 7 is pre-computed on a discrete $3 \mathrm{D}$ cubic grid whose reciprocal extent is determined by the detector and beam parameters. Once the resulting diffraction volume is available in memory, it can readily be sliced at an arbitrary orientation and curvature in two steps. First, the detector pixels are mapped to their corresponding positions in the reciprocal volume. Second, the complex structure factor at each pixel is estimated through trilinear interpolation. The resulting diffraction intensities are then adjusted to account for beam polarization, solid angle distortion, and diverse sources of noise.

Usage. The Python script below illustrates how the modularity of skopi is implemented in practice. Classes for the beam, particle and detector are instantiated and given to the experiment class, which in turn generates diffraction patterns.

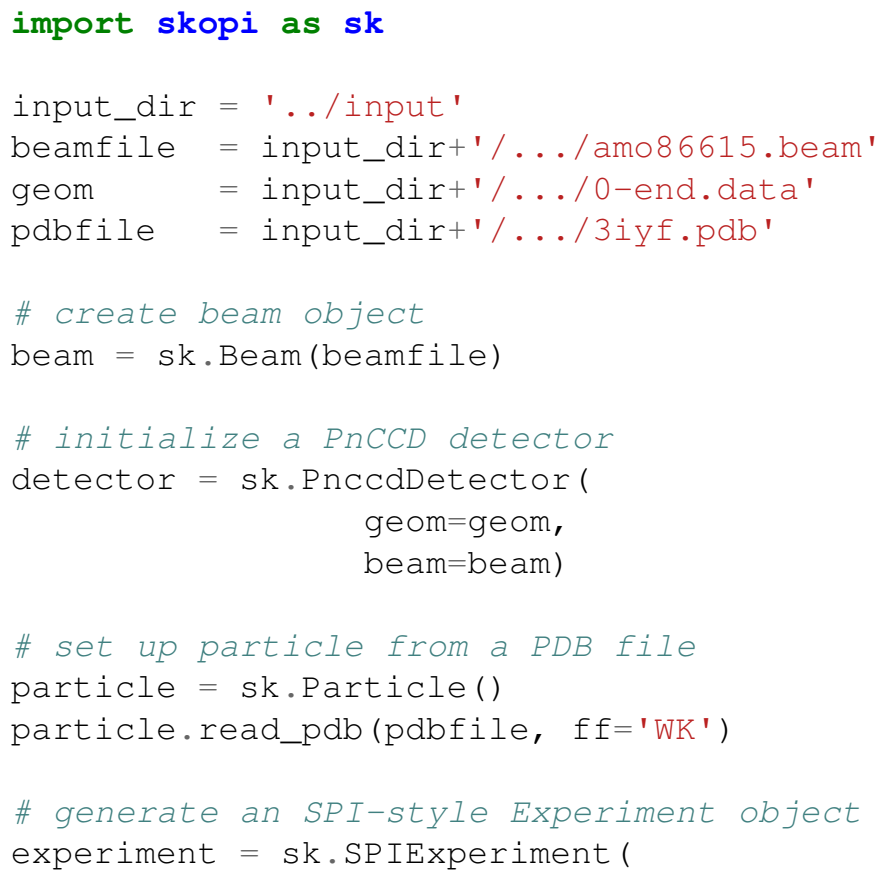

det $=$ detector,

beam=beam,

particle=particle)

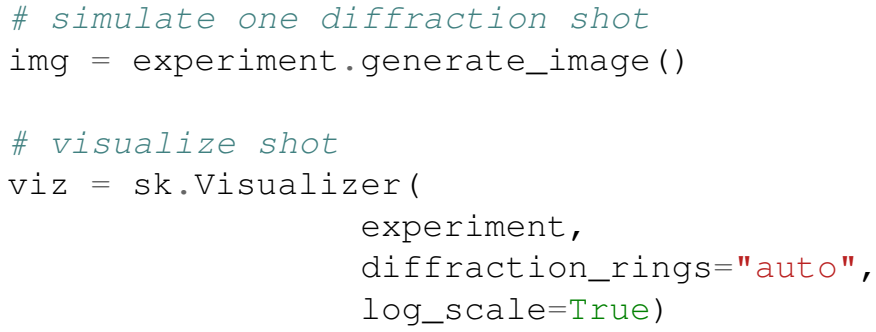

viz.imshow (img)

Acknowledgements

We thank Haoyuan Li and Juncheng E for their contributions to the code. This research was supported by the Exascale Computing Project (17-SC-20-SC), a collaborative effort of the U.S. Department of Energy Office of Science and the National Nuclear Security Administration. Use of the Linac Coherent Light Source (LCLS), SLAC National Accelerator Laboratory, is supported by the U.S. Department of Energy, Office of Science, Office of Basic Energy Sciences under Contract No. DEAC02-76SF00515.

\section{References}

Assalauova, D., Kim, Y. Y., Bobkov, S., Khubbutdinov, R., Rose, M., Alvarez, R., Andreasson, J., Balaur, E., Contreras, A., DeMirci, H., Gelisio, L., Hajdu, J., Hunter, M. S., Kurta, R. P., Li, H., McFadden, M., Nazari, R., Schwander, P., Teslyuk, A., Walter, P., Xavier, P. L., Yoon, C. H., Zaare, S., Ilyin, V. A., Kirian, R. A., Hogue, B. G., Aquila, A. \& Vartanyants, I. A. (2020). IUCrJ, 7(Pt 6), 1102-1113.

Ayyer, K., Xavier, P. L., Bielecki, J., Shen, Z., Daurer, B. J., Samanta, A. K., Awel, S., Bean, R., Barty, A., Bergemann, M., Ekeberg, T., Estillore, A. D., Fangohr, H., Giewekemeyer, K., Hunter, M. S., Karnevskiy, M., Kirian, R. A., Kirkwood, H., Kim, Y., Koliyadu, J., Lange, H., Letrun, R., Lübke, J., Michelat, T., Morgan, A. J., Roth, N., Sato, T., Sikorski, M., Schulz, F., Spence, J. H., Vagovic, P., Wollweber, T., Worbs, L., Yefanov, O., Zhuang, Y., Maia, F. R. N. C., Horke, D. A., Küpper, J., Loh, N. D., Mancuso, A. P. \& Chapman, H. N. (2020). Optica, 8(1).

Bakan, A., Meireles, L. M. \& Bahar, I. (2011). Bioinformatics, 27(11), 1575-1577.

Bielecki, J., Hantke, M. F., Daurer, B. J., Reddy, H. K. N., Hasse, D., Larsson, D. S. D., Gunn, L. H., Svenda, M., Munke, A., Sellberg, J. A., Flueckiger, L., Pietrini, A., Nettelblad, C., Lundholm, I., Carlsson, G., Okamoto, K., Timneanu, N., Westphal, D., Kulyk, O., Higashiura, A., van der Schot, G., Loh, N. D., Wysong, T. E., Bostedt, C., Gorkhover, T., Iwan, B., Seibert, M. M., Osipov, T., Walter, P., Hart, P., Bucher, M., Ulmer, A., Ray, D., Carini, G., Ferguson, K. R., Andersson, I., Andreasson, J., Hajdu, J. \& Maia, F. R. N. C. (2019). Sci Adv, 5(5), eaav8801.

Bielecki, J., Maia, F. R. N. C. \& Mancuso, A. P. (2020). Struct Dyn, 7(4), 040901.

Blaj, G., Caragiulo, P., Carini, G., Carron, S., Dragone, A., Freytag, D., Haller, G., Hart, P., Hasi, J., Herbst, R., Herrmann, S., Kenney, C., Markovic, B., Nishimura, K., Osier, S., Pines, J., Reese, B., Segal, J., Tomada, A. \& Weaver, M. (2015). Journal of Synchrotron Radiation, 22(3), 577-583.

Brändén, G., Hammarin, G., Harimoorthy, R., Johansson, A., Arnlund, D., Malmerberg, E., Barty, A., Tångefjord, S., Berntsen, P., DePonte, D. P., Seuring, C., White, T. A., Stellato, F., Bean, R., Beyerlein, K. R., Chavas, L. M. G., Fleckenstein, H., Gati, C., Ghoshdastider, U., Gumprecht, L., Oberthür, D., Popp, D., Seibert, M., Tilp, T., Messerschmidt, M., Williams, G. J., Loh, N. D., 
bioRxiv preprint doi: https://doi.org/10.1101/2021.12.09.471972; this version posted December 10, 2021. The copyright holder for this preprint (which was not certified by peer review) is the author/funder, who has granted bioRxiv a license to display the preprint in perpetuity. It is made available under aCC-BY-NC-ND 4.0 International license.

Chapman, H. N., Zwart, P., Liang, M., Boutet, S., Robinson, R. C. \& Neutze, R. (2019). Nat Commun, 10(1), 2589.

Chen, M. \& Ludtke, S. J. (2021). Nature Methods, 18(8), 930-936.

Cruz-Chú, E. R., Hosseinizadeh, A., Mashayekhi, G., Fung, R., Ourmazd, A. \& Schwander, P. (2021). Struct Dyn, 8(1), 014701.

Daurer, B. J., Okamoto, K., Bielecki, J., Maia, F. R. N. C., Mühlig, K., Seibert, M. M., Hantke, M. F., Nettelblad, C., Benner, W. H., Svenda, M., Tîmneanu, N., Ekeberg, T., Loh, N. D., Pietrini, A., Zani, A., Rath, A. D., Westphal, D., Kirian, R. A., Awel, S., Wiedorn, M. O., van der Schot, G., Carlsson, G. H., Hasse, D., Sellberg, J. A., Barty, A., Andreasson, J., Boutet, S., Williams, G., Koglin, J., Andersson, I., Hajdu, J. \& Larsson, D. S. D. (2017). IUCrJ, 4(Pt 3), 251-262.

Donatelli, J. J., Sethian, J. A. \& Zwart, P. H. (2017). Proc Natl Acad Sci U S A, 114(28), 7222-7227.

Doniach, S. (2018). In X-ray Free Electron Lasers, pp. 427-439. Springer, Cham.

van Driel, T. B., Nelson, S., Armenta, R., Blaj, G., Boo, S., Boutet, S., Doering, D., Dragone, A., Hart, P., Haller, G., Kenney, C., Kwaitowski, M., Manger, L., McKelvey, M., Nakahara, K., Oriunno, M., Sato, T. \& Weaver, M. (2020). J Synchrotron Radiat, 27(Pt 3), 608-615.

Dujardin, A., Slaugther, E., Donatelli, J., Zwart, P., Perazzo, A. \& Yoon, C. H. (2020). In Proceedings of the 19th Python in Science Conference, edited by Meghann Agarwal, Chris Calloway, Dillon Niederhut \& David Shupe, pp. 18 - 23.

Ekeberg, T., Svenda, M., Abergel, C., Maia, F. R., Seltzer, V., Claverie, J. M., Hantke, M., Jönsson, O., Nettelblad, C., van der Schot, G., Liang, M., DePonte, D. P., Barty, A., Seibert, M. M., Iwan, B., Andersson, I., Loh, N. D., Martin, A. V., Chapman, H., Bostedt, C., Bozek, J. D., Ferguson, K. R., Krzywinski, J., Epp, S. W., Rolles, D., Rudenko, A., Hartmann, R., Kimmel, N. \& Hajdu, J. (2015). Phys Rev Lett, 114(9), 098102.

Fortmann-Grote, C., Buzmakov, A., Jurek, Z., Loh, N.-T. D., Samoylova, L., Santra, R., Schneidmiller, E. A., Tschentscher, T., Yakubov, S., Yoon, C. H., Yurkov, M. V., Ziaja-Motyka, B. \& Mancuso, A. P. (2017). IUCrJ, 4(Pt 5), 560-568. 28989713[pmid].

URL: https://pubmed.ncbi.nlm.nih.gov/28989713

Geloni, G., Huang, Z. \& Pellegrini, C. (2017). In X-Ray Free Electron Lasers: Applications in Materials, Chemistry and Biology, pp. 1-44. The Royal Society of Chemistry.

Gorkhover, T., Ulmer, A., Ferguson, K., Bucher, M., Maia, F. R. N. C., Bielecki, J., Ekeberg, T., Hantke, M. F., Daurer, B. J., Nettelblad, C., Andreasson, J., Barty, A., Bruza, P., Carron, S., Hasse, D., Krzywinski, J., Larsson, D. S. D., Morgan, A., Mühlig, K., Müller, M., Okamoto, K., Pietrini, A., Rupp, D., Sauppe, M., van der Schot, G., Seibert, M., Sellberg, J. A., Svenda, M., Swiggers, M., Timneanu, N., Westphal, D., Williams, G., Zani, A., Chapman, H. N., Faigel, G., Möller, T., Hajdu, J. \& Bostedt, C. (2018). Nature Photonics, 12(3), 150-153.

Hantke, M. F., Ekeberg, T. \& Maia, F. R. N. C. (2016). Journal of Applied Crystallography, 49(4), 1356-1362.

URL: https://doi.org/10.1107/S1600576716009213

Hantke, M. F., Hasse, D., Maia, F. R. N. C., Ekeberg, T., John, K., Svenda, M., Loh, N. D., Martin, A. V., Timneanu, N., Larsson, D. S. D., van der Schot, G., Carlsson, G. H., Ingelman, M., Andreasson, J., Westphal, D., Liang, M., Stellato, F., DePonte, D. P., Hartmann, R., Kimmel, N., Kirian, R. A., Seibert, M. M., Mühlig, K., Schorb, S., Ferguson, K., Bostedt, C., Carron, S., Bozek, J. D., Rolles, D., Rudenko, A., Epp, S., Chapman, H. N., Barty, A., Hajdu, J. \& Andersson, I. (2014). Nature Photonics, 8(12), 943949.

Hau-Riege, S. P., London, R. A., Chapman, H. N., Szoke, A. \& Timneanu, N. (2007). Phys Rev Lett, 98(19), 198302.

Ignatenko, A., Assalauova, D., Bobkov, S. A., Gelisio, L., Teslyuk, A. B., Ilyin, V. A. \& Vartanyants, I. A. (2021). Machine Learning: Science and Technology, 2(2), 025014.

URL: https://doi.org/10.1088/2632-2153/abd916

Jamison, S. (2010). Nature Photonics, 4(9), 589-591.

URL: https://doi.org/10.1038/nphoton.2010.210
Kurta, R. P., Donatelli, J. J., Yoon, C. H., Berntsen, P., Bielecki, J., Daurer, B. J., DeMirci, H., Fromme, P., Hantke, M. F., Maia, F. R. N. C., Munke, A., Nettelblad, C., Pande, K., Reddy, H. K. N., Sellberg, J. A., Sierra, R. G., Svenda, M., van der Schot, G., Vartanyants, I. A., Williams, G. J., Xavier, P. L., Aquila, A., Zwart, P. H. \& Mancuso, A. P. (2017). Phys Rev Lett, 119(15), 158102.

Maia, F. R., Ekeberg, T., Tîmneanu, N., van der Spoel, D. \& Hajdu, J. (2009). Phys Rev E Stat Nonlin Soft Matter Phys, 80(3 Pt 1), 031905.

Mandl, T., Östlin, C., Dawod, I. E., Brodmerkel, M. N., Marklund, E. G., Martin, A. V., Timneanu, N. \& Caleman, C. (2020). J Phys Chem Lett, 11(15), 6077-6083.

Mendez, D., Lane, T. J., Sung, J., Sellberg, J., Levard, C., Watkins, H., Cohen, A. E., Soltis, M., Sutton, S., Spudich, J., Pande, V., Ratner, D. \& Doniach, S. (2014). Philosophical Transactions of the Royal Society B: Biological Sciences, 369(1647), 20130315.

Mendez, D., Watkins, H., Qiao, S., Raines, K. S., Lane, T. J., Schenk, G., Nelson, G., Subramanian, G., Tono, K., Joti, Y., Yabashi, M., Ratner, D. \& Doniach, S. (2016). IUCrJ, 3(6), 420-429.

Neutze, R., Wouts, R., van der Spoel, D., Weckert, E. \& Hajdu, J. (2000). Nature, 406(6797), 752-757.

Paganin, D. M. (2006). Coherent $x$-ray optics. Oxford series on synchrotron radiation. Oxford: Oxford University Press.

URL: http://cds.cern.ch/record/1447848

Pande, K., Donatelli, J. J., Malmerberg, E., Foucar, L., Bostedt, C., Schlichting, I. \& Zwart, P. H. (2018). Proc Natl Acad Sci U S A, 115(46), 11772-11777.

Punjani, A. \& Fleet, D. J. (2021). Journal of Structural Biology, 213(2), 107702.

Reddy, H. K., Yoon, C. H., Aquila, A., Awel, S., Ayyer, K., Barty, A., Berntsen, P., Bielecki, J., Bobkov, S., Bucher, M., Carini, G. A., Carron, S., Chapman, H., Daurer, B., DeMirci, H., Ekeberg, T., Fromme, P., Hajdu, J., Hanke, M. F., Hart, P., Hogue, B. G., Hosseinizadeh, A., Kim, Y., Kirian, R. A., Kurta, R. P., Larsson, D. S., Duane Loh, N., Maia, F. R., Mancuso, A. P., Mühlig, K., Munke, A., Nam, D., Nettelblad, C., Ourmazd, A., Rose, M., Schwander, P., Seibert, M., Sellberg, J. A., Song, C., Spence, J. C., Svenda, M., Van der Schot, G., Vartanyants, I. A., Williams, G. J. \& Xavier, P. L. (2017). Scientific Data, 4(1), 170079.

URL: https://doi.org/10.1038/sdata.2017.79

Redford, S., Andrä, M., Barten, R., Bergamaschi, A., Brückner, M., Dinapoli, R., Fröjdh, E., Greiffenberg, D., Lopez-Cuenca, C., Mezza, D., Mozzanica, A., Ramilli, M., Ruat, M., Ruder, C., Schmitt, B., Shi, X., Thattil, D., Tinti, G., Vetter, S. \& Zhang, J. (2018). Journal of Instrumentation, 13(01), C01027-C01027. URL: https://doi.org/10.1088/1748-0221/13/01/c01027

Rose, M., Bobkov, S., Ayyer, K., Kurta, R. P., Dzhigaev, D., Kim, Y. Y., Morgan, A. J., Yoon, C. H., Westphal, D., Bielecki, J., Sellberg, J. A., Williams, G., Maia, F. R. N. C., Yefanov, O. M., Ilyin, V., Mancuso, A. P., Chapman, H. N., Hogue, B. G., Aquila, A., Barty, A. \& Vartanyants, I. A. (2018). IUCrJ, 5(Pt 6), 727-736.

Schlichting, I. (2015). IUCrJ, 2(Pt 2), 246-255.

van der Schot, G., Svenda, M., Maia, F. R., Hantke, M., DePonte, D. P., Seibert, M. M., Aquila, A., Schulz, J., Kirian, R., Liang, M., Stellato, F., Iwan, B., Andreasson, J., Timneanu, N., Westphal, D., Almeida, F. N., Odic, D., Hasse, D., Carlsson, G. H., Larsson, D. S., Barty, A., Martin, A. V., Schorb, S., Bostedt, C., Bozek, J. D., Rolles, D., Rudenko, A., Epp, S., Foucar, L., Rudek, B., Hartmann, R., Kimmel, N., Holl, P., Englert, L., Duane Loh, N. T., Chapman, H. N., Andersson, I., Hajdu, J. \& Ekeberg, T. (2015). Nat Commun, 6, 5704.

Seibert, M. M., Ekeberg, T., Maia, F. R., Svenda, M., Andreasson, J., Jönsson, O., Odić, D., Iwan, B., Rocker, A., Westphal, D., Hantke, M., DePonte, D. P., Barty, A., Schulz, J., Gumprecht, L., Coppola, N., Aquila, A., Liang, M., White, T. A., Martin, A., Caleman, C., Stern, S., Abergel, C., Seltzer, V., Claverie, J. M., Bostedt, C., Bozek, J. D., Boutet, S., Miahnahri, A. A., Messerschmidt, M., Krzywinski, J., Williams, G., Hodgson, K. O., Bogan, M. J., Hampton, C. Y., Sierra, R. G., Starodub, D., Andersson, I., Bajt, S., Barthelmess, M., Spence, J. C., Fromme, P., Weierstall, U., Kirian, R., Hunter, M., Doak, R. B., Marchesini, S., Hau-Riege, S. P., Frank, M., Shoeman, R. L., 
bioRxiv preprint doi: https://doi.org/10.1101/2021.12.09.471972; this version posted December 10,2021 . The copyright holder for this preprint (which was not certified by peer review) is the author/funder, who has granted bioRxiv a license to display the preprint in perpetuity. It is made available under aCC-BY-NC-ND 4.0 International license.

Lomb, L., Epp, S. W., Hartmann, R., Rolles, D., Rudenko, A., Schmidt, C., Foucar, L., Kimmel, N., Holl, P., Rudek, B., Erk, B., Hömke, A., Reich, C., Pietschner, D., Weidenspointner, G., Strüder, L., Hauser, G., Gorke, H., Ullrich, J., Schlichting, I., Herrmann, S., Schaller, G., Schopper, F., Soltau, H., Kühnel, K. U., Andritschke, R., Schröter, C. D., Krasniqi, F., Bott, M., Schorb, S., Rupp, D., Adolph, M., Gorkhover, T., Hirsemann, H., Potdevin, G., Graafsma, H., Nilsson, B., Chapman, H. N. \& Hajdu, J. (2011). Nature, 470(7332), 78-81.

Shi, Y., Yin, K., Tai, X., DeMirci, H., Hosseinizadeh, A., Hogue, B. G., Li, H., Ourmazd, A., Schwander, P., Vartanyants, I. A., Yoon, C. H., Aquila, A. \& Liu, H. (2019). IUCrJ, 6(Pt 2), 331-340.

Spence, J. C. H. (2017). IUCrJ, 4(Pt 4), 322-339.

Spence, J. C. H. (2018). IUCrJ, 5(Pt 3), 236-237.

Stauch, B. \& Cherezov, V. (2018). Annu Rev Biophys, 47, 377-397.

Yoon, C. H., Schwander, P., Abergel, C., Andersson, I., Andreasson, J., Aquila, A., Bajt, S., Barthelmess, M., Barty, A., Bogan, M. J., Bostedt, C., Bozek, J., Chapman, H. N., Claverie, J. M., Coppola, N., DePonte, D. P., Ekeberg, T., Epp, S. W., Erk, B., Fleckenstein, H., Foucar, L., Graafsma, H., Gumprecht, L., Hajdu, J., Hampton, C. Y., Hartmann, A., Hartmann, E., Hartmann, R., Hauser, G., Hirsemann, H., Holl, P., Kassemeyer, S., Kimmel, N., Kiskinova, M., Liang, M., Loh, N. T., Lomb, L., Maia, F. R., Martin, A. V., Nass, K., Pedersoli, E., Reich, C., Rolles, D., Rudek, B., Rudenko, A., Schlichting, I., Schulz, J., Seibert, M., Seltzer, V., Shoeman, R. L., Sierra, R. G., Soltau, H., Starodub, D., Steinbrener, J., Stier, G., Strüder, L., Svenda, M., Ullrich, J., Weidenspointner, G., White, T. A., Wunderer, C. \& Ourmazd, A. (2011). Opt Express, 19(17), 16542-16549.

Yoon, C. H., Yurkov, M. V., Schneidmiller, E. A., Samoylova, L., Buzmakov, A., Jurek, Z., Ziaja, B., Santra, R., Loh, N. D., Tschentscher, T. \& Mancuso, A. P. (2016). Scientific Reports, 6(1), 24791.

URL: https://doi.org/10.1038/srep24791

Zhong, E. D., Bepler, T., Berger, B. \& Davis, J. H. (2021). Nat Methods, 18(2), 176-185.

Östlin, C., Timneanu, N., Caleman, C. \& Martin, A. V. (2019). Struct Dyn, 6(4), 044103. 
bioRxiv preprint doi: https://doi.org/10.1101/2021.12.09.471972; this version posted December 10,2021 . The copyright holder for this preprint (which was not certified by peer review) is the author/funder, who has granted bioRxiv a license to display the preprint in perpetuity. It is made available under aCC-BY-NC-ND 4.0 International license.

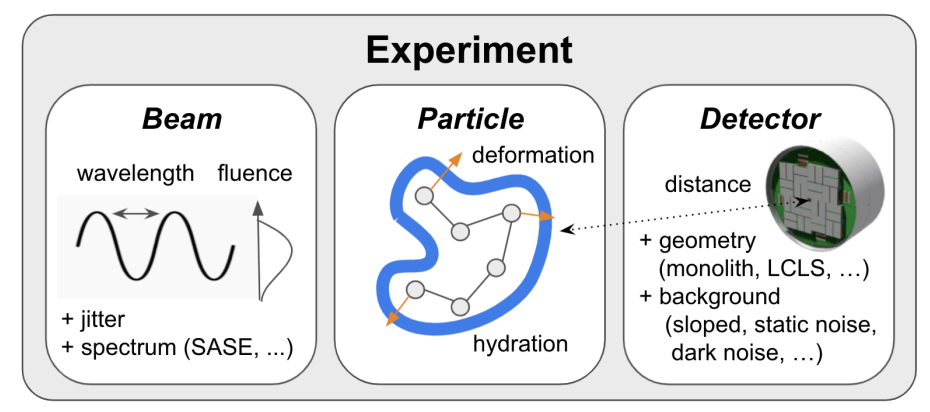

Figure 1

Modular architecture. The three principal components of each experiment - the beam, particle, and detector - are initialized independently of each other. Once these components are set up, diffraction patterns from a range of CXDI experiments can be efficiently simulated.

A.

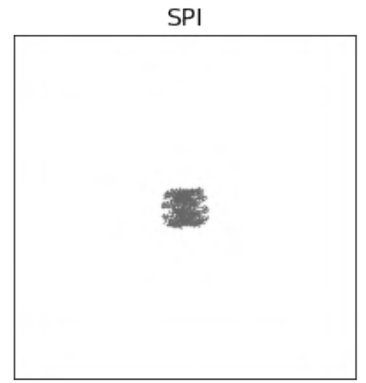

B.

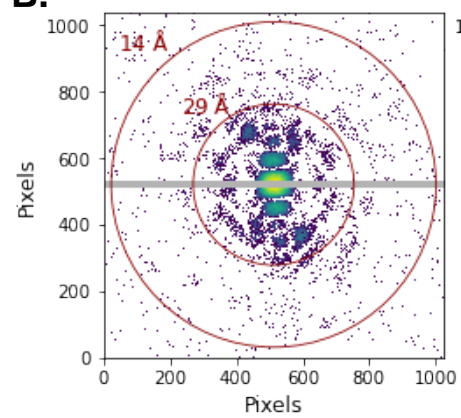

SPI, aggregate

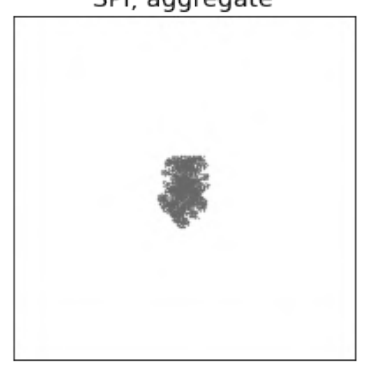

FXS

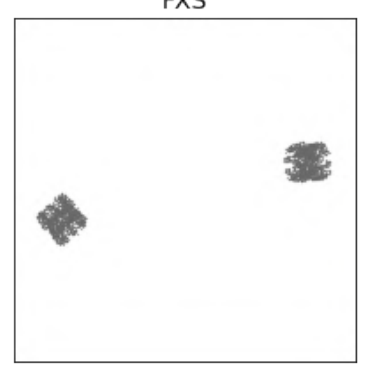

Holography

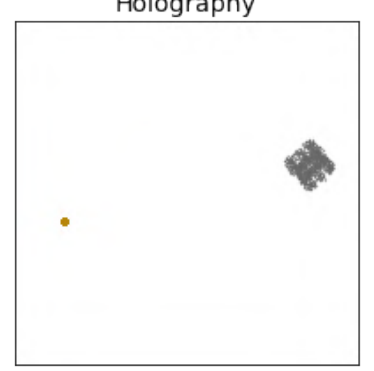

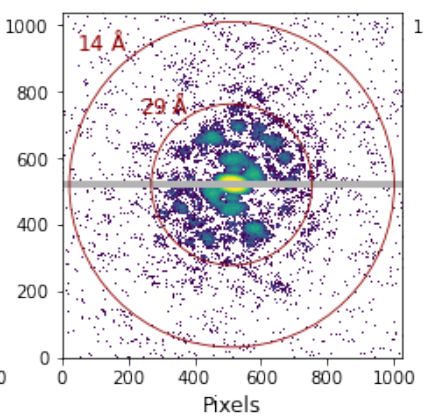
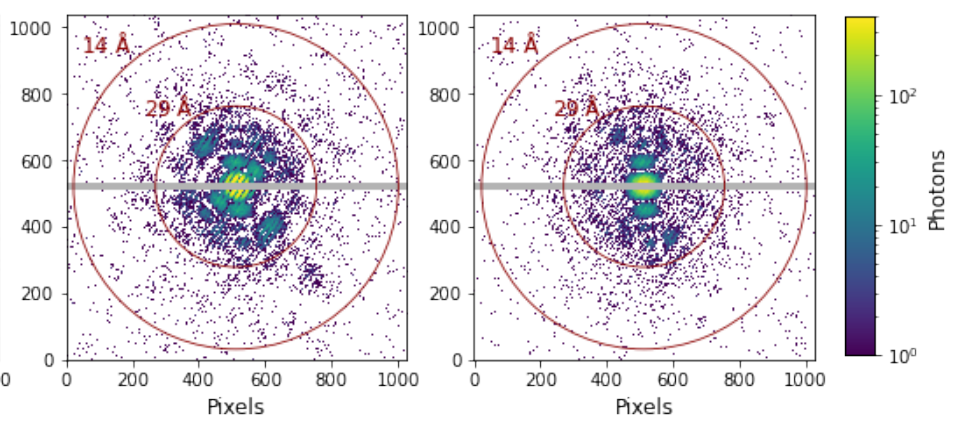

Figure 2

Overview of noncrystalline CXDI experiments. Skopi supports simulations of SPI, FXS, and holography experiments. (A) The projection of the particle(s) in the plane of the beam and (B) the corresponding diffraction patterns are shown for each experiment type. In the case of SPI, either an individual particle or an aggregate can be simulated. In FXS and holography experiments, multiple particles are in the beam; for holography, one of these particles serves as a reference - in this case, a small cluster of gold atoms. The biomolecule used in these simulations is a chaperonin (PDB ID: 3iyf). In (B) the grey region marks the gap between panels of the PnCCD detector. The beam fluence was artificially inflated to aid visualization. 
bioRxiv preprint doi: https://doi.org/10.1101/2021.12.09.471972; this version posted December 10, 2021. The copyright holder for this preprint (which was not certified by peer review) is the author/funder, who has granted bioRxiv a license to display the preprint in perpetuity. It is made available under aCC-BY-NC-ND 4.0 International license.

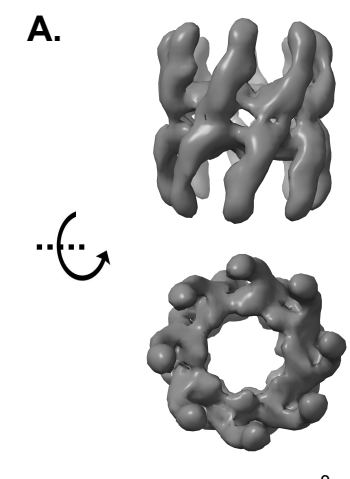

Noise-free $(15 \AA)$

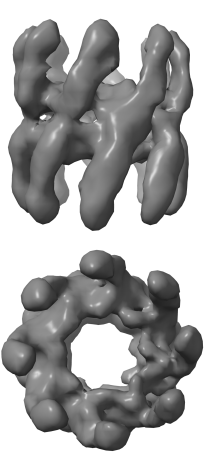

+ Poisson noise (20 A)

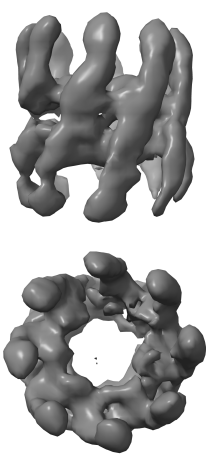

+ Poisson noise
+ Beam jitter (25 $)$
B.

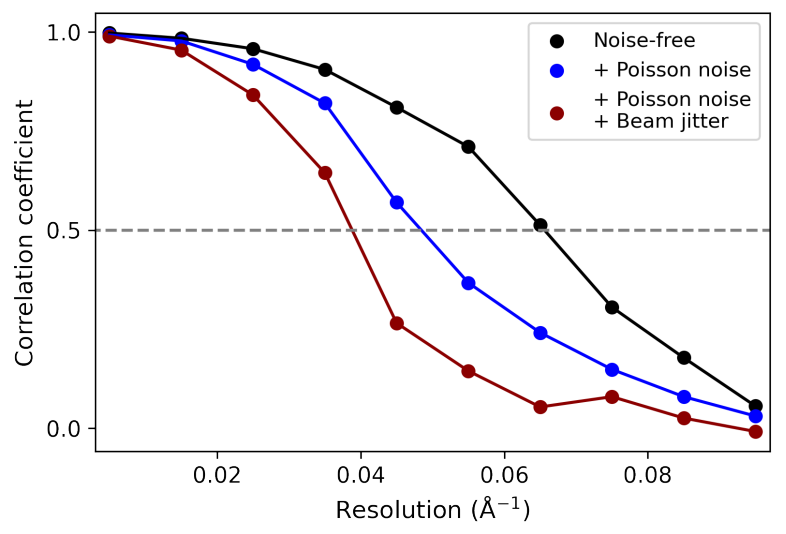

Figure 3

Reconstruction from simulated SPI datasets. SPI datasets of a chaperonin were simulated in the absence or presence of noise. A multi-tiered iterative phasing algorithm was used to recover the protein structure from $5 \mathrm{k}$ images of the indicated dataset. (A) Isosurfaces of the density map reveal the loss of eight-fold symmetry with increasing noise. The resolution of each reconstruction is noted in parenthesis. (B) The resolution was measured as the spatial frequency at which the Fourier shell correlation (FSC) between the reconstructed and reference maps dropped to 0.5 . 
bioRxiv preprint doi: https://doi.org/10.1101/2021.12.09.471972; this version posted December 10, 2021. The copyright holder for this preprint (which was not certified by peer review) is the author/funder, who has granted bioRxiv a license to display the preprint in perpetuity. It is made available under aCC-BY-NC-ND 4.0 International license.

A.
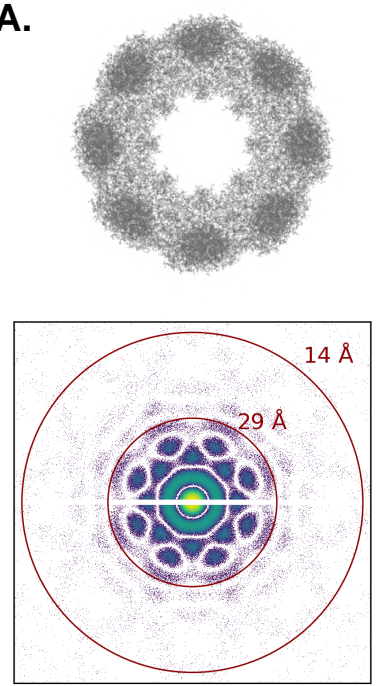

B.
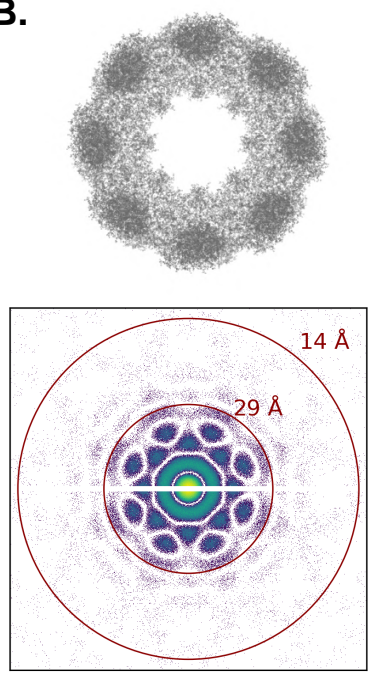
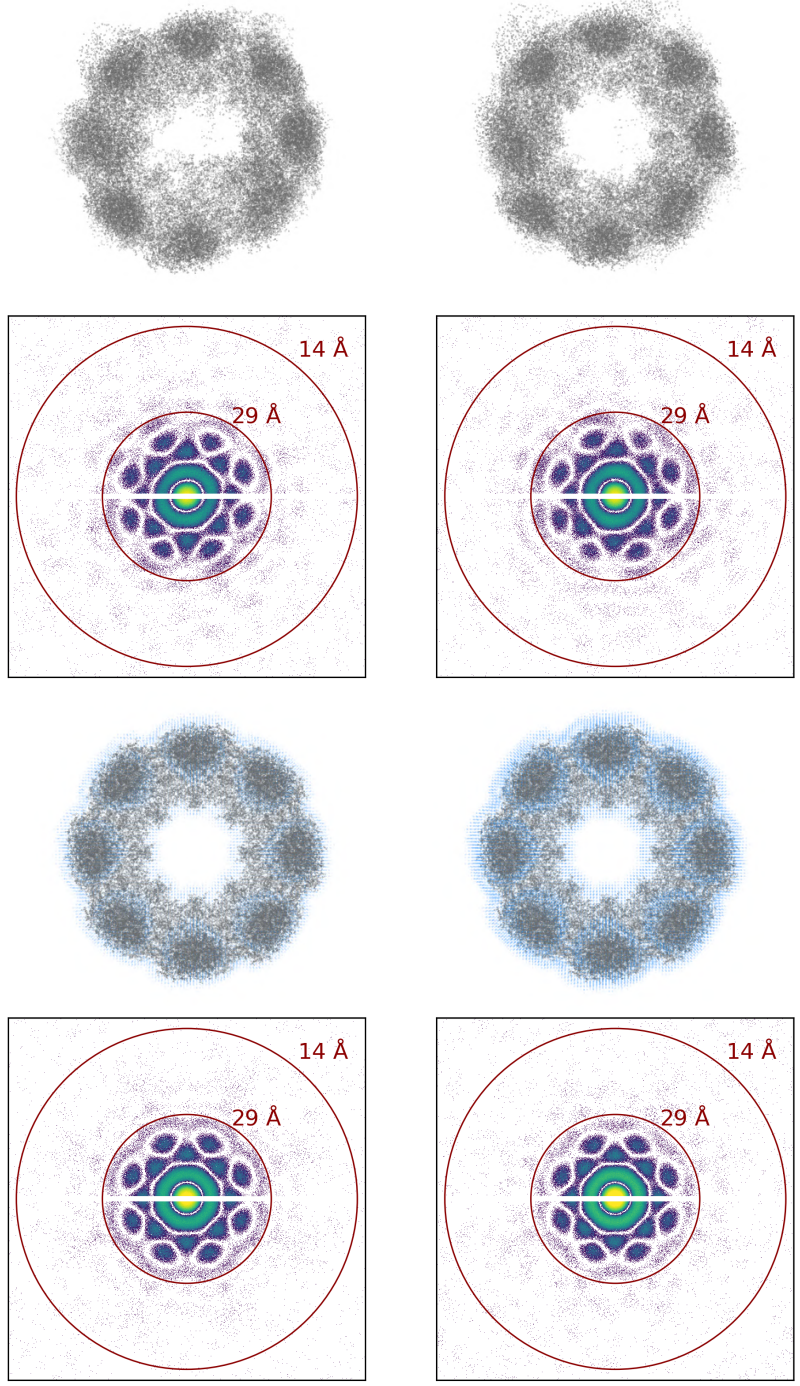
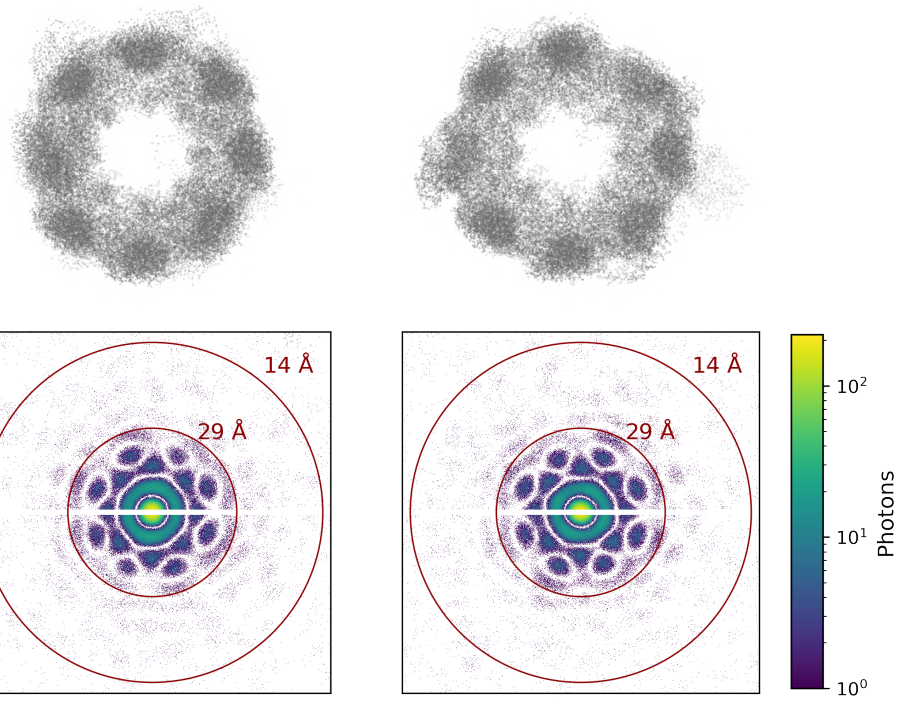
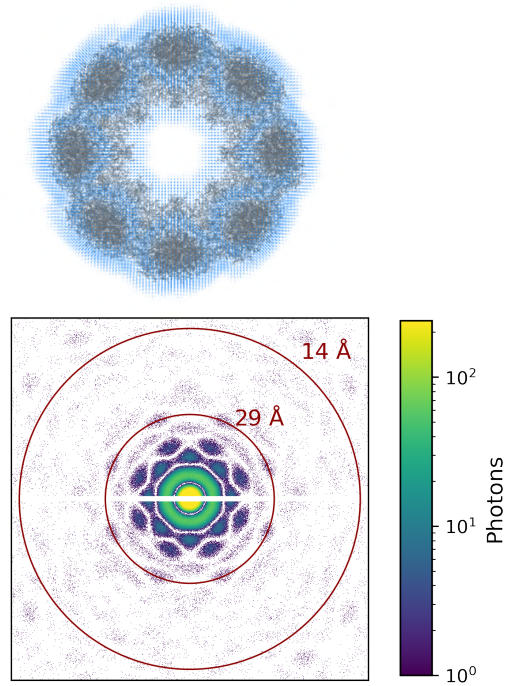

\section{Figure S1}

Sources of sample heterogeneity. (A) Distinct conformations were generated by sampling along the protein's normal modes (upper), and the corresponding diffraction patterns are visualized (lower). Conformational heterogeneity results in visible distortion of the protein's eight-fold symmetry along this axis in the simulated shots. (B) The hydration layer surrounding aerosolized particles is modeled as a disordered solvent shell of variable width that follows the contours of the protein. From left to right, the chaperonin protein (grey, PDB ID: 3iyf) was encased in a solvent shell (blue) of 0, 4, 8, and $12 \AA$ (upper). The diffraction pattern for each solvation state is shown (lower). 
bioRxiv preprint doi: https://doi.org/10.1101/2021.12.09.471972; this version posted December 10, 2021. The copyright holder for this preprint (which was not certified by peer review) is the author/funder, who has granted bioRxiv a license to display the preprint in perpetuity. It is made available under aCC-BY-NC-ND 4.0 International license.

A.

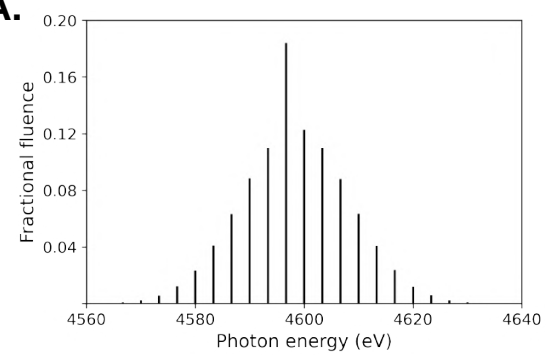

B.

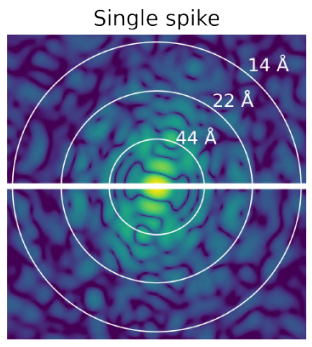

SASE spectrum

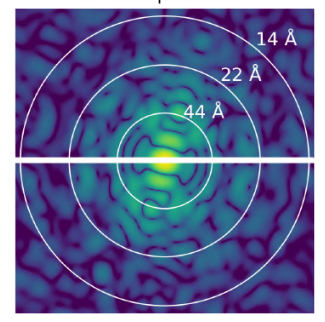

Difference map

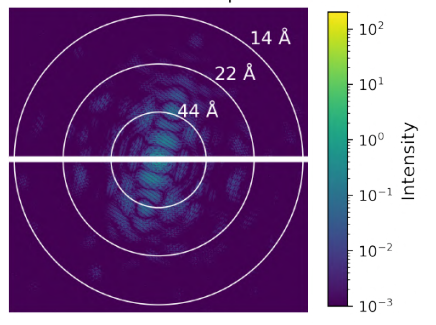

\section{Figure S2}

Modeling the beam as a SASE spectrum. (A) The distribution of spike energies and fractional fluences in a representative SASE spectrum are shown for a mean beam energy of $4600 \mathrm{eV}$. (B) Diffraction patterns for a particle in the same orientation but imaged with either a single, monochromatic spike or a SASE-style beam are compared, with the absolute difference map shown on the right. Because the magnitude of differences is on the same scale as quantization error, intensities rather than photons were computed. However, the source of the difference does not follow a Poisson distribution. 
bioRxiv preprint doi: https://doi.org/10.1101/2021.12.09.471972; this version posted December 10, 2021. The copyright holder for this preprint (which was not certified by peer review) is the author/funder, who has granted bioRxiv a license to display the preprint in perpetuity. It is made available under aCC-BY-NC-ND 4.0 International license.
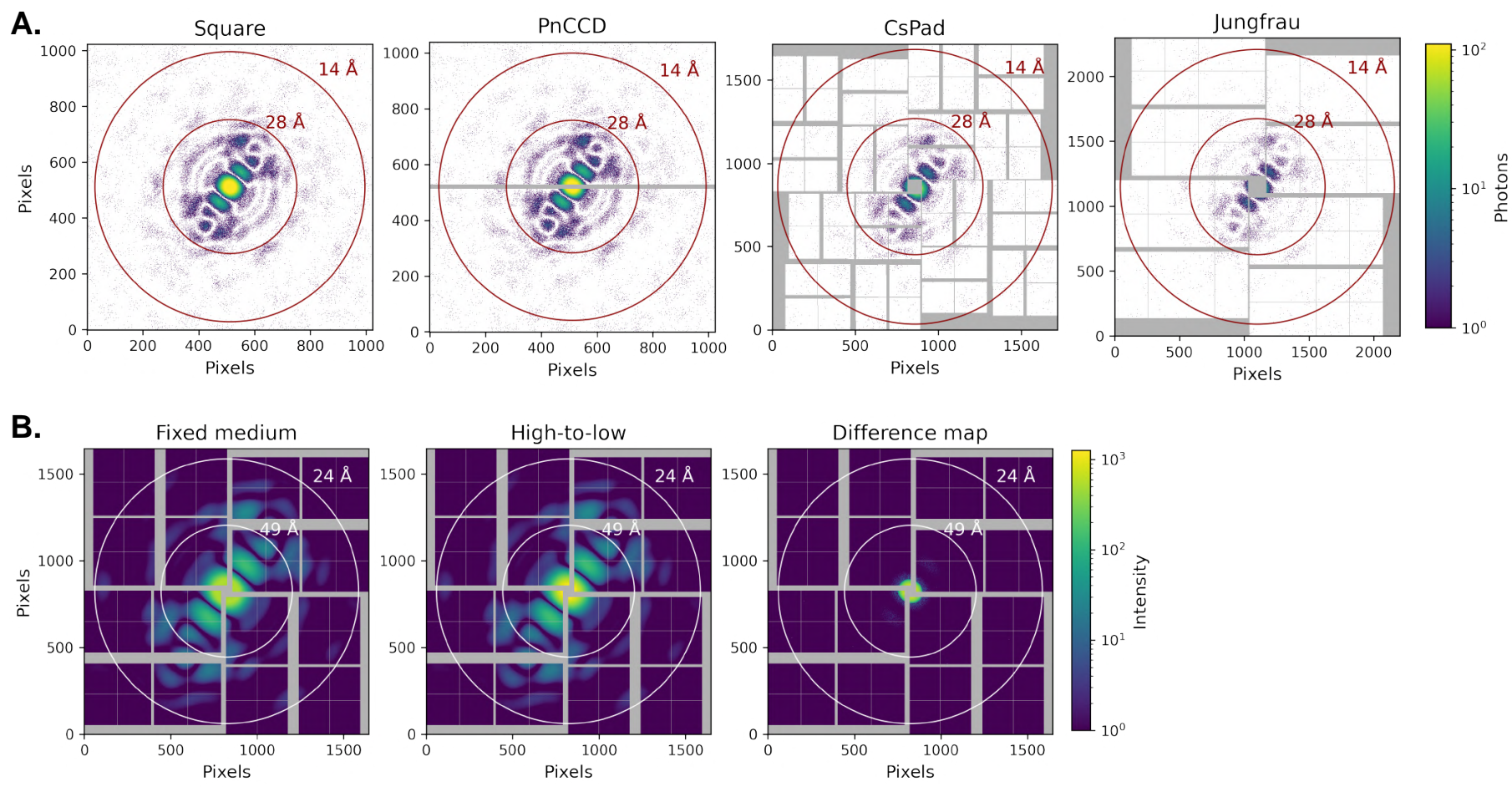

\section{Figure S3}

Support of diverse detector types. (A) In addition to a user-defined monolithic square detector, skopi supports simulating images on a range of LCLS detectors such as the PnCCD, CsPad, and Jungfrau. Diffraction patterns using the same beam and particle objects were simulated on each of these detectors. (B) The recentlydeveloped Jungfrau and Epix10k detectors have an auto-ranging feature with various gain combinations to increase the dynamic range. Diffraction patterns simulated on the Epix10k are compared for the fixed medium and high-to-low gain combinations, showing that the latter mode eliminates saturation at high intensity values. Intensities rather than photons are shown and the detector distance has been adjusted to better illustrate where differences between the gain combination modes are most pronounced. 
bioRxiv preprint doi: https://doi.org/10.1101/2021.12.09.471972; this version posted December 10, 2021. The copyright holder for this preprint (which was not certified by peer review) is the author/funder, who has granted bioRxiv a license to display the preprint in perpetuity. It is made available under aCC-BY-NC-ND 4.0 International license.

A.
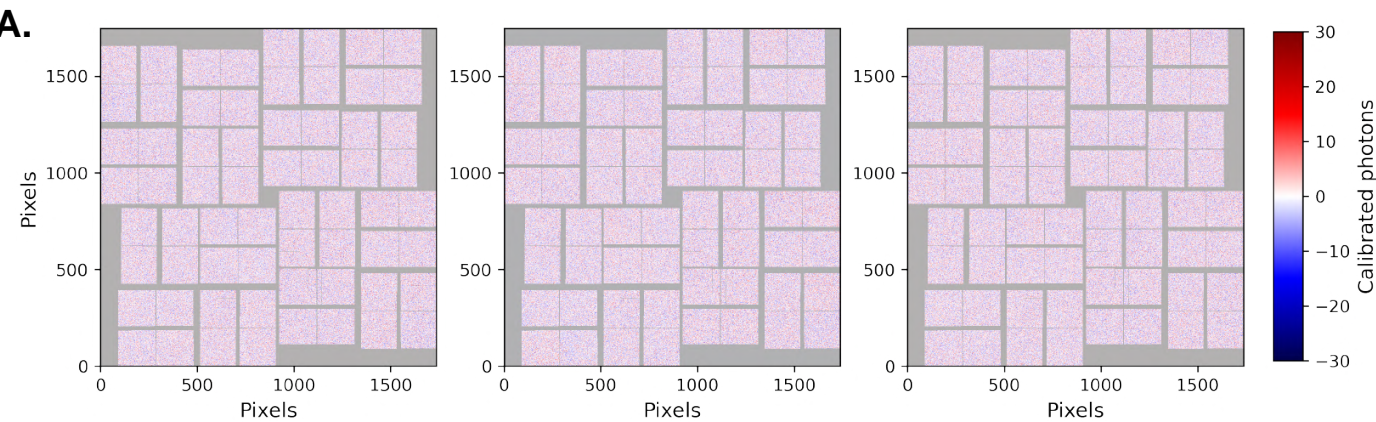

B.
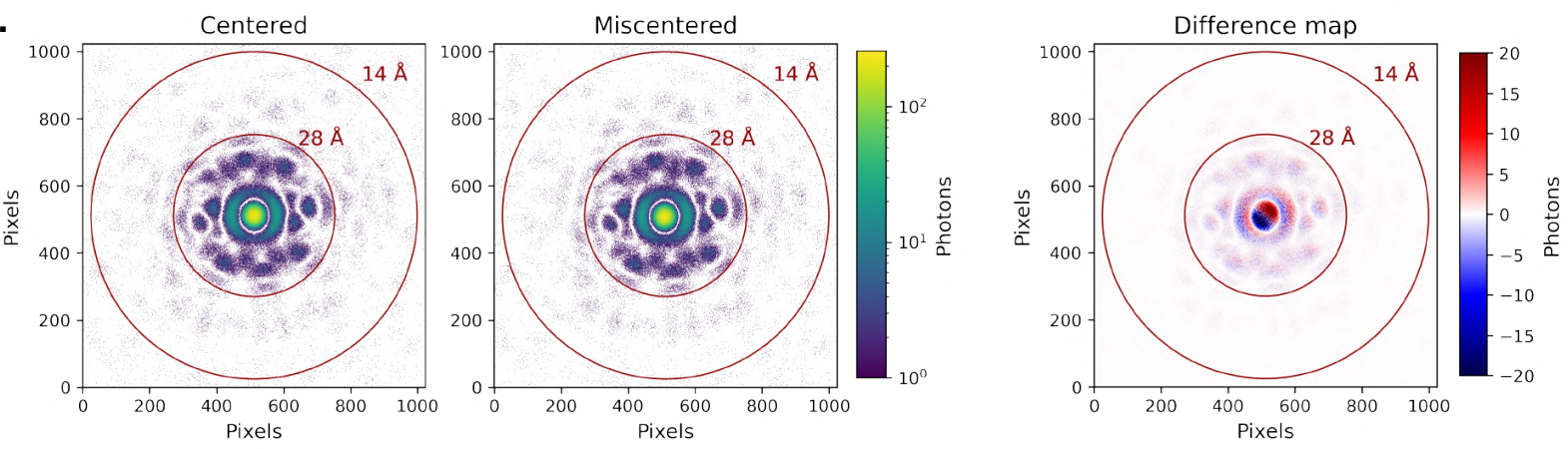

C.
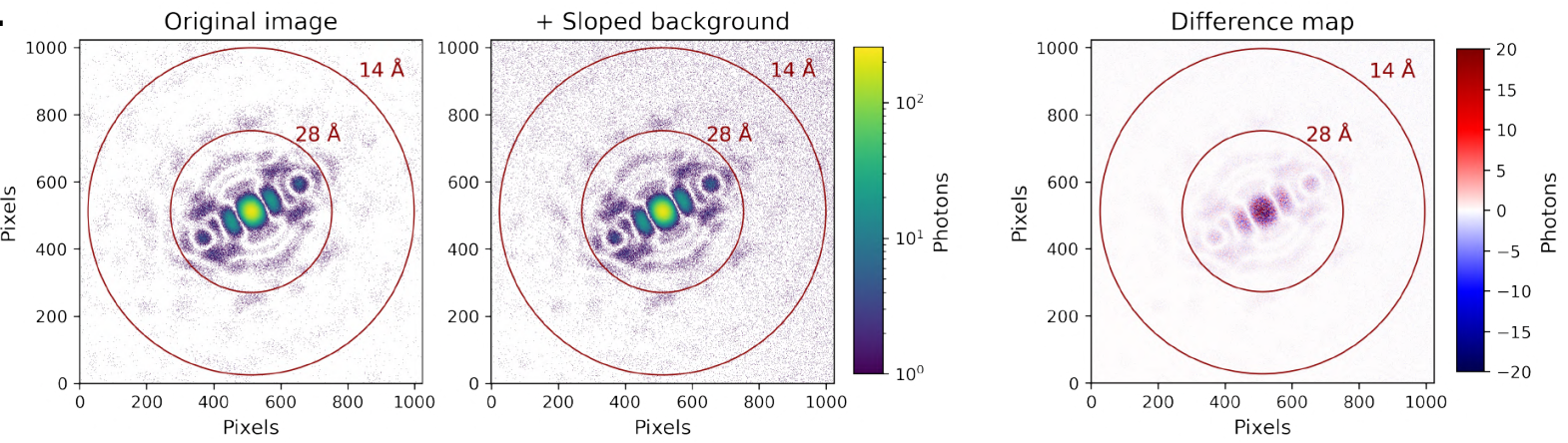

Figure S4

Sources of instrument noise. (A) Representative dark shots are shown from an experiment performed at LCLS on a CsPad detector. The dark noise fluctuates between images, and the counts can be negative due to pedestal subtraction. (B) Beam miscentering and (C) a user-defined sloped background can be introduced as additional sources of noise. Difference maps are shown on a linear scale to aid visual comparison. 
bioRxiv preprint doi: https://doi.org/10.1101/2021.12.09.471972; this version posted December 10,2021 . The copyright holder for this preprint (which was not certified by peer review) is the author/funder, who has granted bioRxiv a license to display the preprint in perpetuity. It is made available under aCC-BY-NC-ND 4.0 International license.
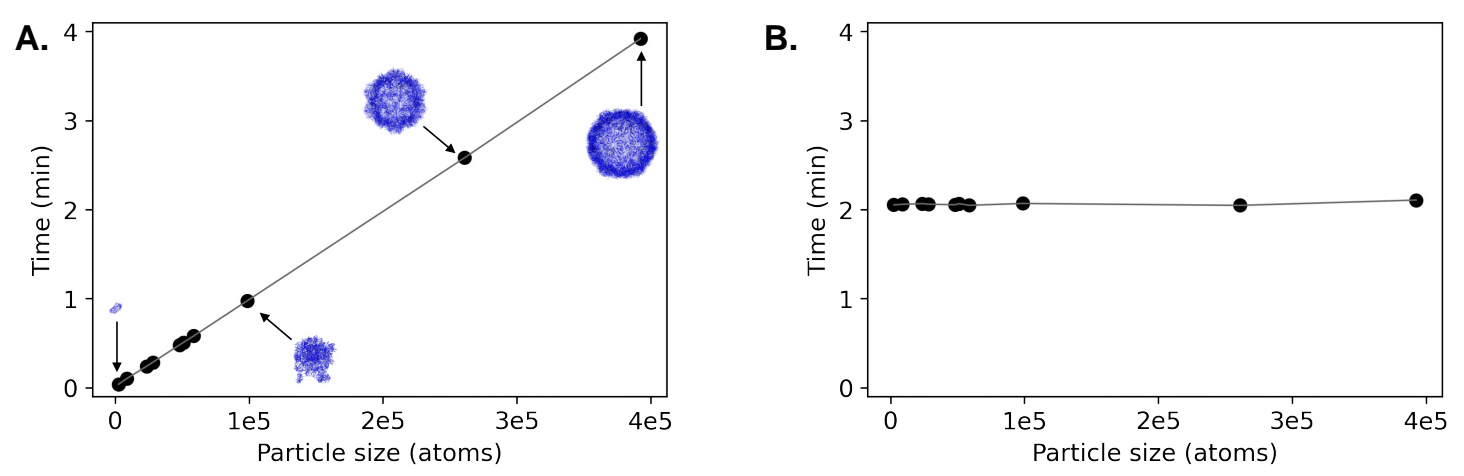

\section{Figure S5}

Scaling of the diffraction calculation with particle size. (A) The time required to initialize a (non-aggregate) SPI experiment is compared for different particle sizes and a square detector of roughly a quarter million pixels. Most of the elapsed time is spent computing the 3D diffraction volume, which scales linearly with particle size and is performed on a single GPU. Models of select particles are shown, from largest to smallest: rhinovirus (PDB ID: 2rmu), feline panleukopenia virus (PDB ID: 1fpv), 50S ribosomal subunit (PDB ID: 3cc4), and sialic acid binding protein (PDB ID: 2cex). (B) The elapsed time to simulate 100 diffraction patterns on a single GPU across a range of particle sizes. Once the experiment is set up, the diffraction image computation time is constant. 